\title{
Empirical Study of Loincloth Typology in Custom-based Marriage in Congo-Brazzaville and Socioeconomic Implications
}

\author{
Moyo Nzololo \\ Correspondence: Moyo Nzololo, Doctor- Assistant at the Faculty of Economic Science, Marien NGOUABI University, \\ ESGAE - Congo Brazzaville.
}

Received: May 17, 2017

doi:10.11114/aef.v4i4.2505

\author{
Accepted: June 1, $2017 \quad$ Available online: June 21, 2017 \\ URL: https://doi.org/10.11114/aef.v4i4.2505
}

\begin{abstract}
Traditional or custom-based marriage is a rejoicing moment that links two families: the paternal and maternal sides of the husband, along with the paternal and maternal sides of the wife. However, the husband-to-be must go through several expenses - in kind and cash - to face a set of lists he is handed over by the paternal and maternal sides of the wife-to-be. Those lists include first-stage preliminary requisites, second-stage marriage requisites, and the dowry requisites. The latter is the most expensive one, despite recommendations from the provisions of the Congolese code of family that sets fifty thousand CFA for the dowry. Such a list clearly indicates the number of loincloths, branded Super Wax, a high-quality and very expensive loincloth. It represents a relatively insuperable obstacle for the husband-to-be. This paper proposes a typology of loincloths from the main components analysis and hierarchical ascending classification applied to a data table crossing twenty-three loincloths and five criteria. It results, from this typology, six scenarios that have socioeconomic implications proposed from the category of prime quality loincloths.
\end{abstract}

Keywords: socioeconomic implications, typology, loincloths, traditional or custom-based marriage, Congolese code of family, quality, main components analysis, hierarchical ascending classification, scenario

\section{Introduction}

The importance of garments, clothes and thus dressing has been underlined by several authors (Grosfilley, 2015; Ayissi, Poinsot, 2015; Moulemvo, 2011; Gherchanoc, Huet, 2007; Depaule, 1990). In Maslow's pyramid of needs, dressing oneself is part of basic physiologic needs, along with other basics such as eating, health care and accommodation. Although a common saying states that "it is not the cowl that makes the friar", the latter is nevertheless recognized through that cowl. This means that dressing is a sign of social distinction. As pinpointed by Jolivet-Jacquet (2009) on that issue, "In addition to being an envelope against weather conditions, it identifies, classes, categorizes, places men within or outside groups".

The Women's international Day is celebrated every March 8 of the year by all the women in Congo, notably by wearing a loincloth. On that occasion, several loincloths are on sale in markets with various and different patterns, designs and colors, with "8-March Day", "March-8, Women's International Day" or "Women's international Day" printed on the loincloth. Wearing the loincloth is a reminder not only that woman is the mother of society, but also that woman gets dressed with dignity and respect, and that woman is proud to be a woman, whether she is a young lady or an adult.

However, the loincloth is no longer used as just a woman's cloth. Dressmakers and designers propose loincloth-made dresses as men's wear: pair of shorts, trousers, shirt, shirt-trousers suit or shirt-shorts suit. It is interesting to notice that made-to-order dressing is one of the main ways to purchase new clothes. This somehow calls into question the second-hand clothes market, that is, second-hand clothes coming from Europe (Bredeloup, Lombard, 2008). Not only the men's wear made from loincloth are inexpensive, but they also make it possible for men to dress relax, which is very important when it is hot; a heat that waves between $28^{\circ} \mathrm{C}$ and $32^{\circ} \mathrm{C}$. Such loincloth-made dresses are very convenient when paying someone a visit, attending family ceremonies, or staying at home. One can easily notice that there are a lot of public transport drivers (taxis, public taxis, minivans and buses) who wear loincloth-made dresses as their working uniforms, notably with short-sleeved shirts (Moyo Nzololo, 2008).

In a comprehensive marriage process, three stages can be noticed: the custom-based marriage, then the official marriage and the religious one. A lot of Congolese people - especially the youth - find it difficult to engage in the process, as the custom-based marriage is source of heavy and numerous expenses. Given that it is up to the man to marry the woman, 
he must - first of all - go through the custom-based marriage from the paternal side, prior to going through the maternal side.

Custom-based marriage from the paternal side includes two steps: first-stage preliminary requisites and second-stage requisites, and then the dowry requisites. Generally, the list of requisites for the first and second stages includes: 12 racks of juice and beer, 3 demijohns of palm wine, 3 demijohns of red wine, 2 bottles of Whisky and 1 bottle of champagne. It is advisable for the husband-to-be to have a sum of FCFA 250,000 as extra money to abide by specific custom requisites.

The list of the dowry items - set by the paternal side - is longer and more expensive than the one set by the maternal side, which implies more expenses. The third stage that goes with the dowry list includes: 25 demijohns of palm wine, 1 demijohn of red wine, 9 racks of beer and juice. The dowry list from the paternal side obviously includes the suit for the father of the wife-to-be, with accessories that go with such a suit. It also includes Super Wax loincloths and head kerchiefs for each of the father's sisters.

Custom-based marriage from the maternal side is about the dowry only. In the dowry list from the maternal side, there is also a third stage that comprises: 12 demijohns of palm wine, 12 demijohns of red wine, 6 racks of beer and juice. The dowry list is reduced; we notably find herein the Super Wax loincloth with its head kerchief for the mother of the wife-to-be, with accessories. Such a list also comprises Super Wax loincloths and head kerchiefs for each of the mother's sisters. The concept of 'sister' is extendable up to cousins who are considered as very close family members.

In most of custom-based marriages, only a symbolic number of demijohns are kept, the rest being converted into the number of beer and juice racks. The presents - that constitute the dowry from the paternal side - are divided into eighteen rubrics or heads, versus eight rubrics from the maternal side. The last rubric or head in both lists is the amount of the dowry paid in cash (Kounzila, 2016). The provisions of Article 140 of the Congolese Family state that the amount of the dowry in cash to be paid shall not exceed FCFA 50,000 (CCdlF, 1984). But actually, there are several families that multiply this amount by 6 , and even more. The sum requested by the maternal side is generally half the one requested by the paternal side.

The custom-based marriage may occur successively (at the paternal side first, prior to going to the maternal side) or simultaneously, which means that both sides of wife 's parents get together at the paternal place, depending on financial capabilities of the husband-to-be. Whatever stage it is, both the family of the husband-to-be and that of the wife-to-be are represented by a traditional spokesman or mediator called «nzonzi » who will be co-chairing the ceremony, speaking on behalf of the two families. One of the ceremony's most expected moments - notably by women who are always outnumbered - is when loincloths are presented, prior to being given to the wife's family. Those women make sure that the required number of loincloths and their quality is respected. In all families and during custom-based marriage ceremonies, the quality demanded for the loincloth is - and must be - branded super wax. It is the most expensive loincloth, that is, FCFA 65,000. Women are accustomed to detecting the genuine super wax brand and the bogus or counterfeit one. Literature on counterfeiting of luxury products is abundant (Moyo Nzololo, 2016a; Maman-Larraufie, 2015). Therefore, the husband-to-be could not venture himself into committing the insult of inserting a counterfeit loincloth amongst the genuine ones. This would immediately disqualify not only himself, but also his entire family and his friends that came with him at such a solemn ceremony.

Based on our knowledge, there is no study that has been conducted, as agreed. In fact, the subject matter concerns an economic issue which is prevailing in Congo -Brazzaville.

Broadly speaking, there is the weight of tradition in one hand, and the reality of the economic situation which accounts for a lower purchasing power of the populations and the rise of the level youth unemployment rate. Those young legitimately desire to get married according to their customs.

The main objective of this paper is to show that custom-based requisites for loincloths can evolve, so as to reduce the economic impact of such a traditional or custom-based marriage. To do so, we seek two specific objectives: the first one is to show that it is possible to find prime-quality loincloths other than super wax; the second one consists in elaborating scenarios that aim at reducing both the economic cost of custom-based marriage in general and the dowry list in particular.

We have two research questions:

- Is it possible to find loincloths that substitute non-counterfeit loincloths branded super wax?

- Can the two mediators, customarily called "nzonzi", mutually agree upon a list of loincloths that are substitutes of super wax?

We have put forward two hypotheses: 
- The first hypothesis is to state that the typologies of loincloth containing super wax provided by the Main Components Analysis (ACP) and Hierarchical Ascending (CAH) methods, propose substitute loincloths whose quality level will have to be specified.

- The second hypothesis is to state that it is possible to elaborate scenarios to be considered by both mediators in order to agree on an acceptable list of loincloths whose cost will be affordable for the husband-to-be. A scenario imagined looks for possible future prospects. That approach is forcefully subjective but has an advantage of considering the future as brightly open. In terms of negotiation such attitude is valuable.

The paper deals with a two-dimension issue. It targets custom-based marriage as a social institution determining the union of two families, that is, the paternal and maternal sides of husband and wife. Moreover, it analyzes transactions in kind and cash - that enable such custom-based marriage.

\section{Material and Method}

\subsection{Material}

Located in Poto Poto center of the third district of Brazzaville, « rue Mbakas » - a name given to that shopping street - is the area where loincloths are mainly sold, both in bulk and in retail. According to a survey carried on sellers, the criteria to be considered by women to appreciate the quality of a loincloth are the following: price, brightness, breadth, durability and transparency.

The brightness of a loincloth may be low, medium or high: it expresses the brilliance of a loincloth. But as it is often said, "all that glitter is not gold".

The breadth of a loincloth may be low, medium or high: a loincloth which has a high breath is easy to be sewed as no additional piece is required. Furthermore, when the woman puts it around her hips, the loincloth oversteps the knees; and it won't look like a miniskirt or a mini-robe.

The durability of a loincloth may be short, medium or high: when such a loincloth is washed, it remains solid; it neither deteriorates, nor fades, and colors remain firmly fixed.

The transparency of a loincloth may be light, medium or high or marked: when transparency is light, this means that the loincloth is respectful of woman's intimacy. As a matter of fact, a transparent loincloth reveals undergarments of a woman who wears such a loincloth.

We have elaborated an $X=(23,5)$ data table with twenty-three loincloths for lines, and the five aforementioned criteria for columns. As far as the price of the loincloths is concerned, we have considered their retail selling price. As for the four other variables, we have codified each of them on a Likert scale: Low/ Short / light $=1$, Average =2 High / Marked $=3$

Table 1. Criteria-based assessment of loincloths

\begin{tabular}{llllll}
\hline Loincloth brand & Price in FCFA & brightness & breadth & Durability & Transparency \\
\hline Super Wax & 65,000 & 2 & 3 & 3 & 1 \\
Dutch Vlisco Wax & 45,000 & 2 & 3 & 3 & 1 \\
Dutch Super Java & 30,000 & 3 & 3 & 3 & 1 \\
Tchiganvi & 15,000 & 2 & 3 & 2 & 2 \\
1Q Uniwax & 30,000 & 2 & 3 & 2 & 1 \\
1Q 2T Woodin & 25,000 & 1 & 3 & 2 & 1 \\
1Q Bogolan & 30,000 & 2 & 3 & 2 & 1 \\
Coton piqué (quilted cotton) & 20,000 & 1 & 3 & 2 & 1 \\
Satin-like cotton & 25,000 & 3 & 3 & 3 & 2 \\
1Q Woodin Uni & 30,000 & 2 & 3 & 2 & 2 \\
Sotexci & 12,000 & 2 & 3 & 2 & 2 \\
Quali Wax & 20,000 & 2 & 3 & 2 & 2 \\
Hitarget & 10,000 & 2 & 3 & 2 & 2 \\
Super sosso & 6,500 & 3 & 1 & 2 & 1 \\
Sultana & 3,000 & 3 & 1 & 2 & 2 \\
Java Hitarget & 15,000 & 2 & 3 & 2 & 2 \\
Super novo & 15,000 & 3 & 3 & 2 & 2 \\
Real block & 15000 & 2 & 3 & 2 & 2 \\
Wax block Hitarget & 15,000 & 3 & 1 & 2 & 2 \\
Super vasco & 15,000 & 2 & 3 & 2 & 2 \\
2Q Woodin & 15,000 & 3 & 3 & 2 & 2 \\
2Q Uniwax & 15,000 & 3 & 3 & 2 & 2 \\
2Q Bogolan & 15,000 & 3 & 3 & 2 & \\
\hline
\end{tabular}

Source : our survey 
We have considered a sample of twelve women that sell loincloths. We have taken two precautions: they have to make the twenty-three loincloths available, and to be sold in retail price. Selling on retail corresponds to a short circuit that puts in contact the seller and the consumer. In fact, the husband-to-be must bring loincloths which have different colors and designs or patterns. Consequently, he must not go to see wholesalers. With each of the women, we took time to fill out the data table based on an average of a 45-minute semi-directing talk. From our talks with the sellers, five key observations come out:

- $\quad$ Three genuine loincloths are made in the Netherlands and sold in Brussels: Super wax, Dutch vlisco wax and Dutch super java;

- Seven genuine loincloths are made in West Africa: in Ghana, in Côte d'Ivoire, in Senegal and in Mali: first-quality plain woodin, first-quality two-stroke woodin, first-quality bogolan, first-quality uniwax, tchiganvi, coton piqué (quilted cotton), and satin-like cotton ;

- $\quad$ Four counterfeit loincloths, labeled as second-quality ones (2Q) are made in the aforementioned West African countries: 2Q plain woodin, 2Q two-stroke woodin, 2Q bogolan , 2Q uniwax ;

- The genuine loincloth labeled "Sotexci" is made in Democratic Republic of Congo;

- All the other loincloths from China, India and Thailand, are counterfeit from the Dutch genuine loincloths which are super wax, Dutch vlisco wax, and Dutch super java (De Ravignan, 2005; Toulabor, 2012). The loincloth labeled "sultana" is a counterfeit one from Pakistan.

At the end of our survey, we built a final data table, table I, where each of the ninety-two filled boxes - the twenty-three boxes of the price column excluded - are made up of each average calculated out of the twelve tables, and rounded at the higher integer above 0.5 , otherwise we consider the whole part. The first column on prices has been filled once and for all. The table lines are called individuals, statistical units or observations. The columns are called variables, criteria or characters.

\subsection{Method}

We have processed the final data table, table I, through two complementary multidimensional data analysis methods: the normed Main Component Analysis (ACP) method and the Hierarchical Ascending Classification (CAH) method. The commonality of both methods is that they put together the individuals that are alike (Escofier, Pagès, 2016). This will make it possible for us to validate - or not to validate - our first hypothesis. To implement the two methods, XLSTAT software has been used.

\section{Results and Discussion}

We successively present the results in relation to Main Component Analysis (ACP) and then in relation to Hierarchical Ascending Classification (CAH), prior to ending by a results discussion.

\subsection{ACP Results}

We have made a Main Component Analysis (ACP) on centered and reduced variables.

Table 2. Main values

\begin{tabular}{llllll}
\hline & F1 & F2 & F3 & F4 & F5 \\
\hline Main value & 2.898 & 1.112 & 0.582 & 0.271 & 0.138 \\
Variability (\%) & 57.961 & 22.234 & 11.632 & 5.413 & 2.759 \\
Accrued \% & 57.961 & 80.195 & 91.828 & 97.241 & 100.000 \\
\hline
\end{tabular}

Source: XLSAT

This table shows that the main factorial plan (F1, F2) holds $80.195 \%$ of the overall information contained in the data table. We can therefore limit the analysis to the main plan (F1, F2) formed by the first two main components or main axes which respectively keep an amount of information: QI $(\mathrm{F} 1)=57.961 \%$ and

$\mathrm{QI}(\mathrm{F} 2)=22.234 \%$.

Table 3. Contributions of variables $(\%)$

\begin{tabular}{llllll}
\hline & F1 & F2 & F3 & F4 & F5 \\
\hline Price & 25.858 & 4.030 & 8.031 & 55.359 & 6.722 \\
Brightness & 7.577 & 59.632 & 16.283 & 0.007 & 16.502 \\
Breadth & 15.488 & 13.997 & 67.009 & 0.736 & 2.770 \\
Durability & 23.042 & 21.957 & 2.072 & 2.302 & 50.626 \\
Transparency & 28.036 & 0.383 & 6.604 & 41.597 & 23.380 \\
\hline
\end{tabular}

Source : XLSTAT 
This table shows that F1 axis is called Transparency, given that it is the variable (28.036\%) which best contributes to the emergence of this first main component, and that F2 axis is called Brightness, as it is the variable (59.632\%) which best contributes to the emergence of this second main component.

Table 4. Coordinates of observations

\begin{tabular}{llllll}
\hline Observation & F1 & F2 & F3 & F4 & F5 \\
\hline Super Wax & -3.600 & 1.139 & -0.879 & 1.417 & 0.032 \\
Dutch Vlisco Wax & -2.822 & 0.832 & -0.445 & 0.279 & 0.428 \\
Dutch Super Java & -1.795 & 1.845 & 0.530 & -0.588 & 0.072 \\
Tchiganvi & 0.387 & -0.789 & 0.354 & 0.090 & 0.319 \\
1Q Uniwax & -1.166 & -0.445 & -0.442 & -0.236 & -0.864 \\
1Q 2TWoodin & -1.414 & -1.766 & -0.983 & -0.508 & -0.110 \\
1Q Bogolan & -0.197 & -0.558 & 0.029 & 0.944 & 0.021 \\
Coton piqué (quilted cotton) & -1.220 & -1.842 & -0.875 & -0.792 & -0.011 \\
Satin-like cotton & -1.600 & 1.768 & 0.638 & -0.873 & 0.171 \\
1Q Woodin uni & -1.166 & -0.445 & -0.442 & -0.236 & -0.864 \\
Quali Wax & 0.192 & -0.712 & 0.245 & 0.375 & 0.219 \\
Hitarget & 0.581 & -0.866 & 0.462 & -0.194 & 0.418 \\
Sotexci & 0.503 & -0.835 & 0.419 & -0.080 & 0.378 \\
Super sosso & 2.329 & 1.435 & -1.243 & -0.661 & 0.327 \\
Sultana & 4.507 & 0.221 & -1.018 & 0.659 & -0.308 \\
Java Hitarget & 0.387 & -0.789 & 0.354 & 0.090 & 0.319 \\
Super nouvo & 0.830 & 0.455 & 1.004 & 0.077 & -0.336 \\
Real block & 0.387 & -0.789 & 0.354 & 0.090 & 0.319 \\
Wax block Hitarget & 1.999 & 1.566 & -1.427 & -0.177 & 0.159 \\
Super vasco & 0.387 & -0.789 & 0.354 & 0.090 & 0.319 \\
2Q Woodin & 0.830 & 0.455 & 1.004 & 0.077 & -0.336 \\
2Q Uniwax & 0.830 & 0.455 & 1.004 & 0.077 & -0.336 \\
2Q Bogolan & 0.830 & 0.455 & 1.004 & 0.077 & -0.336 \\
\hline XISAT & & & & &
\end{tabular}

Source : XLSAT

This table makes it possible to elaborate two loincloth typologies: first, in relation to F1 axis, and then in relation to F2 axis.

\subsubsection{Loincloth Typology in Relation to F1 Axis}

G1 $=\{$ Super wax, Dutch Vlisco Wax, Dutch Super Java, 1Q Uniwax, 1Q 2T Woodin, 1QBogolan, Coton piqué (quilted cotton), Satin-like cotton, 1Q Woodin Uni\} contains the loincloths that hold a negative coordinate on F1 axis. These are loincloths that have low transparency. All of them are genuine ones. Their transparency is so low that their coordinate on the axis is minor.

G2 = \{Tchiganvi, Quali Wax, Hitarget, Sotexci, Super sosso, Sultana, Super nouvo, Real block, Wax block Hitarget, Super vasco, 2Q Woodin, 2Q Uniwax, 2Q Bogolan \} contains the loincloths that hold a positive coordinate on F1 axis. These are loincloths that have high transparency. Their transparency is so high that their coordinate on F1 axis is large.

\subsubsection{Loincloth typology in relation to F2 axis}

G3 $=\{$ Super Wax, Dutch Vlisco Wax, Dutch Super Java, Super sosso, Sultana, Super novo, Wax block Hitarget, 2Q Woodin, 2Q Uniwax, 2Q Bogolan \} contains loincloths that hold a positive coordinate on F2 axis. These are loincloths with high brightness. Their brightness is so high that their coordinate on the axis is large or big.

G4 = \{Tchiganvi, 1Q Uniwax, 1Q 2T Woodin, 1Q Bogolan, Coton piqué (quilted cotton), 1Q Woodin uni, Quali Wax, Hitarget, Sotexci, Java Hitarget, Real block, Super vasco \} contains loincloths that hold a negative coordinate on F2 axis. These are loincloths with low brightness. Their brightness is so low that their coordinate on the axis is minor. 


\subsection{Results from the Hierarchical Ascending Classification (CAH) Method}

Referring to economic literature, quality is product's vertical differentiation criteria. Three classes of products are generally noticed: top-of-the-range, mid-range and bottom-of-the-range, or prime quality, intermediate quality and low-grade (Coestier, Marette, 2004; Stanziani, 2008). We have therefore, and beforehand, considered three classes. We have done a Hierarchical Ascending Classification $(\mathrm{CAH})$ on centered and reduced variables, whose dissimilarity indice is the Euclidean distance and Ward method as aggregation method.

Table 5. Core objects

\begin{tabular}{llllll}
\hline Class & Price & Brightness & Breadth & Durability & Transparency \\
\hline 1(Dutch Vlisco Wax) & 45000,000 & 2,000 & 3,000 & 3,000 & 1,000 \\
2 (Quali Wax) & 20000,000 & 2,000 & 3,000 & 2,000 & 2,000 \\
3 (Super sosso) & 6500,000 & 3,000 & 1,000 & 2,000 & 2,000 \\
\hline
\end{tabular}

Source : XLSTAT

This table shows that each of the three classes is identified by its core object:

The core object for Class 1 is Dutch Vlisco Wax, the core object for Class 2 is Quali Wax, and the core object for Class 3 is Super sosso. The loincloths belonging to a given class look like its core object.

Table 6. Results per objet

\begin{tabular}{ll}
\hline Observation & Class \\
\hline Super Wax & 1 \\
Dutch Vlisco Wax & 1 \\
Dutch Super Java & 1 \\
Tchiganvi & 2 \\
1Q Uniwax & 2 \\
1Q 2TWoodin & 2 \\
1Q Bogolan & 2 \\
Coton piqué (quilted cotton) & 2 \\
Satin-like cotton & 1 \\
1Q Woodin Uni & 2 \\
Quali Wax & 2 \\
Hitarget & 2 \\
Sotexci & 2 \\
Super sosso & 3 \\
Sultana & 3 \\
Java Hitarget & 2 \\
Super nouvo & 2 \\
Real block & 2 \\
Wax block Hitarget & 3 \\
Supervasco & 2 \\
2Q Woodin & 2 \\
2Q Uniwax & 2 \\
2Q Bogolan & 2 \\
\hline
\end{tabular}

\section{Source : XLSTAT}

This table sets the loincloths per class:

Class 1 (Dutch Vlisco Wax) $=$ \{Super Wax, Dutch Vlisco Wax, Dutch Super Java, Satin-like cotton $\}$. Class1, that has Dutch Vlisco Wax as core object, contains the following four loincloths: Super Wax, Dutch Vlisco Wax, Dutch Super Java, Satin-like cotton. These are prime-quality loincloths, notably in terms of breadth, durability and transparency.

Class $2($ Quali wax $)=\{$ Tchiganvi, 1Q Uniwax , 1Q 2T Woodin, 1Q Bogolan, Coton piqué (quilted cotton), 1Q Woodin Uni, Quali Wax, Hitarget, Sotexci, Java Hitarget, Super nouvo, Real Block, Super vasco, 2Q Woodin, 2Q Uniwax, 2Q Bogolan\}. The core object of Class 2 is Quali Wax, which is an intermediate-quality counterfeit loincloth. Out of 16 loincloths within this class, there are six genuine loincloths and ten counterfeit ones. Class 2 contains intermediate-quality loincloths as they have an average durability.

Classe 3 (Super sosso) $=\{$ Super sosso, Sultana, Wax block Hitarget $\}$. The core object of Class 3 is Super sosso which is a low-grade loincloth. Class 3 contains three loincloths which are low-graded ones, notably because of their low breadth. 


\section{Discussion}

Groups and classes that are devoid of the Super Wax loincloth are not concerned with the discussion. As a matter of fact, we are seeking loincloths that can substitute Super wax and which - obviously - belong to the same groups or classes as Super wax. Consequently, we do not consider group G2, group G4, class 2 and Class 3 in our discussion.

The Main Component Analysis (ACP) method has provided with two groups of loincloths that look like the Super Wax loincloth.

In relation to $\mathrm{F} 1$, it is about:

G1 $=\{$ Super wax, Java, Dutch Vlisco Wax, Dutch Super Java, 1Q Uniwax, 1Q 2T Woodin, 1Q Bogolan, Coton piqué (quilted cotton), Satin-like cotton, 1Q Woodin Uni\}. These are loincloths that have minor transparency.

In relation to $\mathrm{F} 2$, it is about:

G3 $=\{$ Super Wax, Dutch Vlisco Wax, Dutch Super Java, Super sosso, Sultana, Super novo, Wax block Hitarget, $2 Q$ Woodin, 2Q Uniwax, 2Q Bogolan\}. These are loincloths with a higher brightness. Their brightness is so high or marked that their coordinate on the axis is large.

Table 7. Square cosines of observations

\begin{tabular}{llllll}
\hline & F1 & F2 & F3 & F4 & F5 \\
\hline Super Wax & 0.761 & 0.076 & 0.045 & 0.118 & 0.000 \\
Dutch Wax Vlisco & 0.874 & 0.076 & 0.022 & 0.009 & 0.020 \\
Dutch Super Java & 0.444 & 0.469 & 0.039 & 0.048 & 0.001 \\
Tchiganvi & 0.149 & 0.618 & 0.124 & 0.008 & 0.101 \\
1Q Uniwax & 0.532 & 0.078 & 0.076 & 0.022 & 0.292 \\
1Q 2T Woodin & 0.315 & 0.491 & 0.152 & 0.041 & 0.002 \\
1Q Bogolan & 0.031 & 0.251 & 0.001 & 0.717 & 0.000 \\
Coton piqué (quilted cotton) & 0.237 & 0.541 & 0.122 & 0.100 & 0.000 \\
Satin-like cotton & 0.372 & 0.454 & 0.059 & 0.111 & 0.004 \\
1Q Woodin Uni & 0.532 & 0.078 & 0.076 & 0.022 & 0.292 \\
Quali Wax & 0.047 & 0.639 & 0.076 & 0.177 & 0.061 \\
Hitarget & 0.223 & 0.495 & 0.141 & 0.025 & 0.115 \\
Sotexci & 0.199 & 0.547 & 0.138 & 0.005 & 0.112 \\
Super sosso & 0.567 & 0.215 & 0.161 & 0.046 & 0.011 \\
Sultana & 0.926 & 0.002 & 0.047 & 0.020 & 0.004 \\
Java Hitarget & 0.149 & 0.618 & 0.124 & 0.008 & 0.101 \\
Super nouvo & 0.341 & 0.102 & 0.498 & 0.003 & 0.056 \\
Real block & 0.149 & 0.618 & 0.124 & 0.008 & 0.101 \\
Wax block Hitarget & 0.468 & 0.287 & 0.239 & 0.004 & 0.003 \\
Supervasco & 0.149 & 0.618 & 0.124 & 0.008 & 0.101 \\
2Q Woodin & 0.341 & 0.102 & 0.498 & 0.003 & 0.056 \\
2Q Uniwax & 0.341 & 0.102 & 0.498 & 0.003 & 0.056 \\
2Q Bogolan & 0.341 & 0.102 & 0.498 & 0.003 & 0.056 \\
\hline XISTAT & & & &
\end{tabular}

Source : XLSTAT

In the light of Table 7, in relation to F2, it is useless to consider group G3 given that the link with F2 measured by the square cosine between the Super Wax loincloth and F2 is almost null (equals 0.076).

The loincloth typology provided by the Hierarchical Ascending Classification (CAH) method - and which implies the Super Wax loincloth - tallies Class 1 (Dutch Vlisco Wax) $=\{$ Super Wax, Dutch Vlisco Wax, Dutch Super Java, Satin-like cotton\}.

In short, we have thus identified a typology that includes two categories of loincloth in relation to the Super Wax loincloth: category T1 coming from the Main Component Analysis (ACP) method, and category T2 provided by the Hierarchical Ascending Classification (CAH) method.

Considering:

$\mathrm{T} 1=\{$ Super wax, Dutch Vlisco Wax, Dutch Super Java, 1Q Uniwax, 1Q 2T Woodin, 1Q Bogolan, Coton piqué (quilted cotton), Satin-like cotton, 1Q Woodin Uni\}.

$\mathrm{T} 2=\{$ Super Wax, Dutch Vlisco Wax, Dutch Super Java, Satin-like cotton $\}$.

We notice that T2 is included in T1. This implies that category T2 is much thinner than $\mathrm{T} 1$. We can therefore focus our discussion on $\mathrm{T} 2$. 
Let us consider that the number of Super wax loincloths requested by both sides equals nine.

Consequently, negotiation between the two mediators representing the two families on the number of loincloths will be based upon Category $\mathrm{T} 2$.

In terms of socioeconomic implications, we propose scenarios of the reduction of dowry expenses according to both the number of loincloths requested and the price for those loincloths.

Table 8. Scenarios for total cost reduction of the list of dowry's loincloths

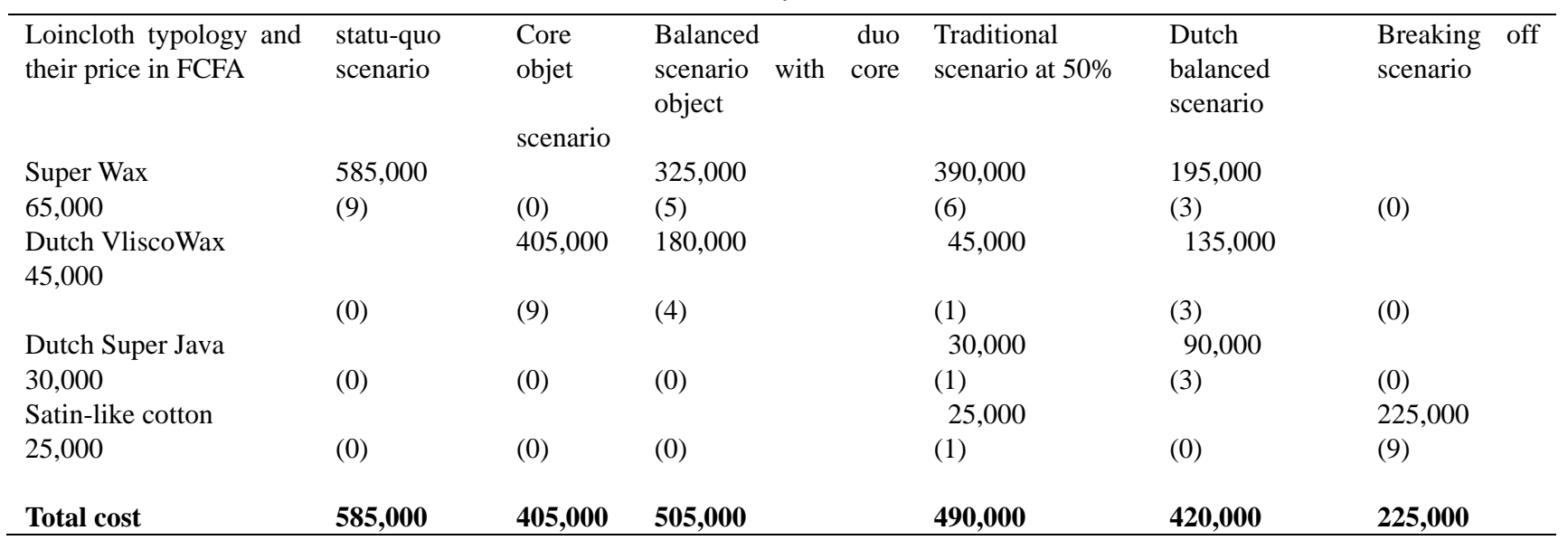

Source: ourselves ()$=$ number of loincloths considered

The statu-quo scenario is a conservative scenario of tradition where the loincloths requested and to be given are labeled Super Wax. It is the scenario where the total cost is higher, that is, FCFA 585,000. It is the scenario that hinders the will of youths to face the dowry list.

The core object consists in giving the loincloth which has the strongest link in T typology with Super Wax and which would therefore be its best substitute: it is the Dutch Vlisco Wax loincloth, as shown on the data table. It is a scenario that makes it possible for the tradition to evolve. The overall cost is FCFA 405,000.

These first two scenarios mutually exclude one another. They are based upon the vertical differentiation of loincloths, not upon physical features that are the same (brightness, breadth, durability, transparency), but rather upon subjective features, that is, brand image: it is higher for Super wax than for Dutch Vlisco Wax; hence the price gap. Therefore, the price will exert discrimination between consumers, enabling the selection of those which access each quality level (Huynh, Besancenot, 2004).

The balanced duo with core object scenario allocates the number of loincloths requested in an almost equal manner between Super wax and Dutch Vlisco Wax which is its best substitute and, at the same time, the core object of the category. The total cost is FCFA 505,000.

The traditional scenario at 50\% is a conservative scenario within which 50\% of loincloths are Super Wax, in the framework of abiding by the tradition; and this scenario is open to change with the other $50 \%$ of the loincloths. The total cost is FCFA 490,000.

The Dutch balanced scenario is a scenario that intends to at least abide by the custom or tradition, while being open to change. It limits itself to the choice of the three prime-quality loincloths of the typology which are the three Dutch genuine cloths. The total cost is FCFA 420,000.

The breaking off scenario is the one which is based on the reality of the typology which puts together individuals that are alike. Given that the satin-like cotton is in the same category of loincloth as Super wax, it is an acceptable substitute. Moreover, it is a scenario where the total cost is more affordable, that is, FCFA 225,000, which is encouraging for a young boy who is willing to face the dowry list.

\section{Conclusion}

We have shown in this paper that in the dowry list for a traditional or custom-based marriage, the unit price of the Super Wax loincloth is very high - FCFA 65,000 - and its renowned prime quality weighs much when considering the total amount of the list according to the number of loincloths requested by the in-laws, both from the paternal and maternal sides. It proves to be part of difficult obstacles to be overcome by the husband-to-be.

In a data table of loincloths that comprises both the Super Wax and other loincloths, we have applied two methods of individuals gathering in order to identify loincloth typologies linked to the Super Wax loincloth. The idea is to state that 
a typology that contains loincloths wherein there is Super Wax puts together loincloths which look like the Super Wax. We have shown the existence of such typology made up of two categories of loincloths, that is, Category T1 comes from the normed Main Component Analysis (ACP) in one hand, and from Category T2 provided by the Hierarchical Ascending Classification (CAH) in another hand. As Category T2 is included in Category T1, it is therefore thinner.

To sum up, Category T2:

- provides a set of prime quality loincloths;

- recalls that price is not the only valuation criterion for the quality of a loincloth;

- gives pieces of information on considered loincloths;

- contributes to encourage the evolvement of tradition of custom-based marriage, with the help of the mediators and open-minded families;

- enlightens possible negotiation scenarios for mediators.

As far as negotiation between the two mediators is concerned, we have proposed a spectrum of scenarios with a total cost that waves between FCFA 585,000 and 225,000. There are two contrasted scenarios: the statu-quo which is the most expensive and which will continue to be an obstacle in the dowry list, and the breaking-off scenario which is inexpensive and which enables the custom to considerably evolve toward a desired future.

We would have talked about luxury products as far as the loincloths of category T2 are concerned. A research trend on luxury associates a luxury product - above all - with part of a dream attached to both its name and the universe it symbolizes (Valette-Florence, 2015). In fact, in the custom-based marriage, on the maternal and paternal sides of the wife-to-be, the dream of paternal aunts, the mother and her sisters, is to wear this mythical luxury loincloth which is the super wax. Luxury is generally associated with high price and prime quality. Yet what is expensive is not always a guarantee of prime quality. That is what is raised by the Gresham law about the bad currency which hunts or chases the good one and, notably in the context of counterfeiting (Moyo Nzololo, 2016b). Thus, to give chance to the breaking-off scenario, it seems to be important for us to insist on prime quality criteria - among which that of durability - met by all the T2 loincloths, and which, for that matter, contribute to the achievement of the dream. It is also possible to consider, having in mind the evolution of society, a global breaking-off scenario with a sole dowry list, reduced and written according to the Congolese family code (Kounzila, 2016).

\section{References}

Ayissi, I., \& Poinsot, M. (2015). Paris, terre d'accueil pour les créateurs africains ? Hommes \& Migrations, 1310(2), 71-74. https://doi.org/10.4000/hommesmigrations.3156

Bredeloup, S., \& Lombard, J. (2008). Mort de la fripe en Afrique ou fin d'un cycle ? Revue Tiers Monde, 194(2); 391-412. https://doi.org/10.3917/rtm.194.0391

[CCdlF] Code Congolais de la Famille (1984). Loi n073/84 du 17/10/1984 portant code de la famille en République du Congo.

Coestier, B., \& Marette, S. (2004). Economie de la qualité. Editions La Découverte, Paris.

De Ravignan, A. (2005). Textile, la déferlante chinoise. Alternatives internationales, 24(5).

Depaule, J. C. (1990). Le vêtement comme métaphore ? Égypte/Monde arabe. Consulté le 13 avril 2017. URL: http://ema.revues.org/228

Escofier, B., \& Pagès, J. (2016). Analyses factorielles simples et multiples. Editions Dunod, Paris.

Gerchanoc, F., \& Huet, V. (2007). Pratiques politiques et culturelles du vêtement. Revue historique, 641(1), 3-30. https://doi.org/10.3917/rhis.071.0003

Grosfilley, A. (2015). Récit d'une vie, tissu d'ailleurs. Des enjeux du wax et des populations noires de France. Hommes \& Migrations, 1310(2), 35 -43. https://doi.org/10.4000/hommesmigrations.3148

Huynh, K., \& Besancenot, D. (2004). Economie industrielle. Editions Bréal, Paris.

Jolivet-Jacquet, S. (2009). Vêtement et textile : sources et ressources. Bulletin du centre d'études médiévales d'Auxerre, 3, 293-302. https://doi.org/10.4000/cem.11088

Kounzila, J. (2016). Le mariage Kongo : rites et symboles. Editions ICES, Paris.

Maman- Larraufie, A. F. (2015). L'achat complice de contrefaçon de luxe en tant qu'expérience de consommation ; quand la raison rencontre les sentiments. Décisions Marketing, 80, 35-51. https://doi.org/10.7193/DM.080.35.52

Moulemvo, A. (2011). Importation de vêtements de seconde main et compétitivité des micro-entreprises de couture au 
Congo-Brazzaville. Revue Congolaise de Gestion, 14(2), 9-33. https://doi.org/10.3917/rcg.014.0009

Moyo, N. (2008). Les transports en commun à Brazzaville à l'horizon 2020. Editions ICES, Corbeil-Essonnes.

Moyo, N. (2016a). Economic analysis of deceptive counterfeiting in Congo Brazzaville. International Research Journal of Marketing and Economics, 3(1), 14-31.

Moyo, N. (2016b). Determination of Characteristic Points and Counterfeiting Market Segmentation in Main Factorial Plan. Applied Economics and Finance, 3(3), 112-116.

Stanziani, A. (2008). La définition de la qualité dans une économie de marché. L'économie politique, 37, 95-112. https://doi.org/10.3917/leco.037.0095

Toulabor, C. (2012). Les Nana Benz de Lomé. Afrique contemporaine, 244(4), 69-80. https://doi.org/10.3917/afco.244.0069

Valette-Florence, P. (2015). Le luxe ou la quête du Saint Graal ...Décisions Marketing, 80, 9-15. https://doi.org/10.7193/DM.080.09.15

\section{Copyrights}

Copyright for this article is retained by the author(s), with first publication rights granted to the journal.

This is an open-access article distributed under the terms and conditions of the Creative Commons Attribution license which permits unrestricted use, distribution, and reproduction in any medium, provided the original work is properly cited. 